ORIGINAL PROF-2189

\title{
CHRONIC KIDNEY DISEASE;
}

\section{CORRELATION BETWEEN FREE THYROXIN, THYROTROPHIN AND GLOMERULAR FILTRATION RATE}

\author{
Dr. Muhammad Asif, Mr. Muhammad Akram, Mr. Atif Ullah.
}

ABSTRACT... Introduction: Chronic kidney disease (CKD) is defined as kidney damage or glomerular filtration rate $<60 \mathrm{ml} / \mathrm{min} / 1.73 \mathrm{~m}^{2}$ for 3 months or more, irrespective of cause. Objective: To measure glomerular filtration rate, free thyroxin, thyrotrophin in chronic kidney disease patients and to find out the correlation between glomerular filtration rate, free thyroxin and thyrotrphin in these patients. Study Design: Cross sectional analytical study. Setting: Post Graduate Medical Institute (PGMI), Lahore General Hospital (LGH) Lahore. Period: 6 months (Nov 2011 to April 2012). Material and Methods: Sixty five patients were included in the study. Serum Creatinine, TSH and Free T4 were measured; Thyroid function tests TSH, FT4 were measured in these chronic kidney disease patients through enzyme linked immunosorbant assay method. GFR was calculated through Cock-croft-Gualt formula and the relevant data was entered in a predesigned Proforma. Results: In the study total 65 chronic kidney disease patients were taken. Out of which thirty six (55.4\%) were male and twenty nine (44.6\%) were female. Thirty five (53.8\%) CKD patients whose TSH levels were above the normal limit while in the remaining patients the TSH values were in the normal range. Eight patients (12.3\%) out of sixty five patients in whom FT4 values were below the normal limit while in the remaining fifty seven patients (87.6\%) FT4 values were within the reference range. Those eight patients whose FT4 was below the normal value, their TSH values were above the normal value too. Thirty five patients, whose TSH levels were above the normal limit, their mean age was 50.60 \pm 11.95 , mean serum creatinine was $4.73 \pm 2.94 \mathrm{mg} / \mathrm{dl}$, mean GFR was $22.17 \pm 12.48 \mathrm{ml} / \mathrm{min} / 1.73 \mathrm{~m}^{2}$, mean TSH was $6.68 \pm 0.87 \mathrm{mlU} / \mathrm{L}$ and mean FT4 was $0.97 \pm 0.35 \mathrm{ng} / \mathrm{dl}$. The $\mathrm{p}$-value of TSH was $<0.001$ and FT4 was $<0.05$ in comparing with normal. Glomerular filtrations rate with TSH and FT4 the co-efficient of correlation (r) value for 35 patients to be -0.713 and 0.47 for TSH and FT4 respectively. Their $p$ - values were 0.000 and 0.004 respectively, and $p<0.001$ collectively. This was found to be statistically significant. Linear regression line was obtained between GFR and TSH and GFR and FT4 in CKD patients. Conclusions: From these correlation studies I concluded that the chronic kidney disease is associated with biochemical thyroid dysfunctions causing most commonly subclinical hypothyroidism.

Key words: Chronic kidney disease, Glomerular filtration rate, Free Thyroxin, Thyrotrophin.

Article Citation

Asif M, Akram M, Ullah A. Chronic kidney disease; correlation between free thyroxin, thyrotrophin and glomerular filtration rate. Professional Med J 2013;20(4): 506-512.

\section{INTRODUCTION}

Chronic kidney disease is a global public health threat associated with an alarming increase in morbidity and mortality. The importance is the worldwide increase in its incidence and prevalence ${ }^{12}$. The major outcomes of chronic kidney disease regardless of cause include progression to kidney failure, complications of decreased kidney function and cardiovascular disease $^{3}$. Chronic kidney disease (CKD) is defined as kidney damage or glomerular filtration rate $<60 \mathrm{ml} / \mathrm{min} / 1.73 \mathrm{~m}^{2}$ for 3 months or more, irrespective of cause. Glomerular filtration rate can be estimated from calibrated serum creatinine and estimating equation like Cockcroft-Gault formula ${ }^{3}$. The interactions between kidney and thyroid functions are known for years. The decline of kidney function is accompanied by changes in the synthesis, secretion, metabolism and elimination of thyroid hormone. Both hypothyroidism and hyperthyroidism affect renal blood flow, glomerular filtration rate, tubular function, electrolytes homeostasis, electrolyte pump functions and kidney structure ${ }^{4}$. In the absence of thyroid disease, patients with non-thyroid illness frequently have changes in serum levels of thyroid hormones that may suggest thyroid dysfunction ${ }^{5}$. Uraemic patients have an increased thyroid volume compared with subjects with normal renal function and a higher prevalence of goiter, mainly in woman. Also, thyroid nodules and thyroid carcinoma are more common in uraemic patients than in the general population. Chronic kidney disease affects both hypothalamuspituitary- thyroid axis and thyroid hormone peripheral 
metabolism ${ }^{4}$.

Thyroid functions are affected by chronic kidney disease in multiple ways, including low circulating thyroid hormone concentration, altered peripheral hormone metabolism and disturbed binding to carrier proteins ${ }^{6}$. It is recognized that patients with subclinical hypothyroidism may have subtle symptoms of thyroid dysfunction; the definition is purely a biochemical one, defined as elevated serum thyrotrophin levels but normal free thyroxin levels. Subclinical hypothyroidism has been recognized in several studies to be associated with markers of cardiovascular risk and cardiac impairment. Even minor deviations from serum TSH normal range might accelerate the development of atherosclerosis and have adverse effects on cardiovascular performance in the general population ${ }^{7}$. It has been suggested that primary hypothyroidism may be more common in patients with end stage renal disease compared with general population. Along with this thyroid hormone abnormalities have been reported among euthyroid patients with end stage renal disease including reduced total and free triiodotyronine and thyroxin levels ${ }^{8}$. In patients with end stage renal disease a variety of alterations in thyroid hormone levels and metabolism have been described ${ }^{9}$.

In the view of above literature the relationship between glomerular filtration rate and thyroid function tests is not clear. Therefore, the present study was planned to determine the correlation between severity of chronic kidney disease and the status of thyroid.

\section{OBJECTIVES}

The objectives of this study were to:

1. Measure the estimated glomerular filtration rate in patients with chronic kidney disease.

2. Measure the free thyroxin and thyrotrophin in chronic kidney disease patients

3. Find out the correlation between the free thyroxin, thyrotrophin and glomerular filtration rate in chronic kidney disease patients.

\section{MATERIAL AND METHOD}

\section{Plan of Study}

The present study included 65 CKD patients. They were taken from the OPD and nephrology ward of General Hospital Lahore. The study was conducted in Post Graduate Medical institute Lahore. The patients were included according to the following criteria

\section{Inclusion criteria}

1) Already diagnosed patients of chronic kidney disease.

2) Both age and sex matched adults $\geq 18-65$ years were included.

\section{Exclusion criteria}

1) The patients with known or clinically suspected thyroid dysfunction.

2) Those patients who have used thyroid hormone or antithyroid medications.

3) Woman with pregnancy.

4) Chronic kidney disease patients on dialysis.

\section{Method of data collection}

After obtaining the informed consent of all the subjects, the personal information of the subjects was recorded on the prescribed Proforma from the predialysis patients.

Venous blood $5 \mathrm{ml}$ was collected in disposable syringe.

Blood was allowed to clot, centrifuged and serum was preserved for TSH, FT4 and serum creatinine estimation. TSH and FT4 were performed in two batchs each separately with their control and standard sera in the kit by ELISA method. ${ }^{10,11,12}$

\section{RESULTS}

In the current study total 65 chronic kidney patients 
were taken. They were subdivided into male and female, thirty six (55.4\%) were male and twenty nine (44.6\%) were female (table-I). According to (table-II) these sixty five chronic kidney disease patients were distributed into five age groups. In first age group (2029years) one (3\%) male and four (14\%) were female. In second age group (30-39 years) four (11\%) male and two (7\%) were female. In third group (40-49years) five (14\%) male and eight (28\%) were female. In fourth group (50-59 years) nine (25\%) male and eleven (38\%) were female. In fifth age group (60-69 years) seventeen (47\%) male and four (14\%) were female.

\begin{tabular}{|c|c|c|}
\hline Gender & n & $\%$ \\
\hline Male & 36 & 55.4 \\
\hline Female & 29 & 44.6 \\
\hline Total & 65 & 100.0 \\
\hline
\end{tabular}

\begin{tabular}{|c|c|c|c|c|c|c|}
\hline \multirow{2}{*}{$\begin{array}{c}\text { Age } \\
\text { (years) }\end{array}$} & \multicolumn{2}{|c|}{ Male } & \multicolumn{2}{c|}{ Female } & \multicolumn{2}{c|}{ Total } \\
\cline { 2 - 7 } & $\mathbf{n}$ & $\%$ & $\mathbf{n}$ & $\%$ & $\mathbf{n}$ & $\%$ \\
\hline $20-29$ & 1 & 3 & 4 & 14 & 5 & 8 \\
\hline $30-39$ & 4 & 11 & 2 & 7 & 6 & 9 \\
\hline $40-49$ & 5 & 14 & 8 & 28 & 13 & 20 \\
\hline $50-59$ & 9 & 25 & 11 & 38 & 20 & 31 \\
\hline $60-69$ & 17 & 47 & 4 & 14 & 21 & 32 \\
\hline Total & 36 & 100 & 29 & 100 & 65 & 100 \\
\hline
\end{tabular}

Table-II. Distribution of chronic kidney disease patients by gender and age
Thyroid functions TSH, FT4 were measured in these chronic kidney disease patients through enzyme linked immunosorbant assay method. Thirty five (53.8\%) CKD patients had TSH was above the normal limit (0.4-6 $\mathrm{mlU} / \mathrm{L})$ while in the remaining patients $\mathrm{TSH}$ value was in normal range. Eight patients (12.3\%) out of sixty five patients in whom FT4 value was below the normal limit $(0.8-2 \mathrm{ng} / \mathrm{dl})$ while in the remaining fifty seven patients (87.6\%) FT4 value was within reference range. Those eight patients whose FT4 was below the normal value, their TSH was above the normal value too. From these values it can be said that twenty seven chronic kidney patients revealed biochemical subclinical hypothyroidism and eight patients revealed biochemical primary hypothyroidism. (Table-III).

\begin{tabular}{|c|c|c|c|c|c|c|c|}
\hline \multicolumn{2}{|c|}{} & \multicolumn{2}{c|}{ Normal } & \multicolumn{2}{c|}{ Decrease } & \multicolumn{2}{c|}{ Total } \\
\cline { 3 - 8 } & $\mathbf{n}$ & $\%$ & $\mathbf{n}$ & $\%$ & $\mathbf{n}$ & $\%$ \\
\hline \multirow{3}{*}{ TSH } & Normal & 30 & 52.6 & 0 & 0 & 30 & 46.2 \\
\cline { 2 - 8 } & Increase & 27 & 47.4 & 8 & 100 & 35 & 53.8 \\
\cline { 2 - 8 } & Total & 57 & 100.0 & 8 & 100 & 65 & 100.0 \\
\hline
\end{tabular}

Table-III. Distribution of CKD patients having deranged TSH and FT4

Chronic kidney disease patients were distributed stage wise, their age, serum creatinine, GFR, TSH and FT4 is shown in table-IV.

Glomerular filtration rate was correlated with TSH and FT4. Co-efficient of correlation ( $r$ ) value of 35 patients was calculated. Co-efficient of correlation of GFR with TSH was -0.713 and GFR with FT4 was 0.471 . Their p-values were 0.000 and 0.004 respectively,

\begin{tabular}{|c|c|c|c|c|c|}
\hline Group & Stage $1(n=1)$ & Stage $2(n=2)$ & Stage $3(n=19)$ & Stage $4(n=24)$ & Stage $5(n=19)$ \\
\hline Age (year) & 37.00 & $37.50 \pm 17.68$ & $51.89 \pm 14.63$ & $52.58 \pm 10.30$ & $48.42 \pm 10.94$ \\
\hline Serum creatinine $(\mathrm{mg} / \mathrm{dl})$ & 1.30 & $1.00 \pm 0.28$ & $2.21 \pm 0.61^{\star}$ & $3.74 \pm 1.03^{*}$ & $7.58 \pm 2.71^{\star}$ \\
\hline GFR $\left(\mathrm{ml} / \mathrm{min} / 1.73 \mathrm{~m}^{2}\right)$ & 91.30 & $71.35 \pm 7.00$ & $41.01 \pm 8.32^{\star}$ & $21.35 \pm 3.59^{*}$ & $10.41 \pm 4.61^{*}$ \\
\hline TSH (mlU/L) & 1.70 & $3.21 \pm 1.99$ & $3.68 \pm 2.31$ & $4.77 \pm 2.41$ & $5.08 \pm 3.0$ \\
\hline FT4 (ng/dl) & 1.80 & $1.82 \pm 0.31$ & $1.12 \pm 0.28^{*}$ & $1.05 \pm 0.24$ & $0.88 \pm 0.33^{*}$ \\
\hline
\end{tabular}

Table-IV. Age, serum creatinine, GFR, TSH and FT4 in chronic kidney disease patients stage wise. mean \pm SD is given. Figure in parenthesis indicate number of cases in each group 
collectively $p<0.001$ which was founded statistically significant (table-V).

\begin{tabular}{|c|c|c|}
\hline & $\begin{array}{c}\text { Coefficient of correlation } \\
(\mathbf{n = 3 5 )}\end{array}$ & P-value \\
\hline GFR with TSH & -0.713 & $0.000^{\star \star}$ \\
\hline GFR with FT4 & 0.471 & $0.004^{\star \star}$ \\
\hline
\end{tabular}

Table-V. GFR was correlated with TSH and FT4. Coefficient

of correlation (r) is given. Figure in parenthesis indicate

number of cases in each group.

${ }^{* *} p<0.01$

Linear regression line was obtained between GFR and TSH in CKD patients. It represents that as GFR decreased TSH was increased. It means that there was inverse relationship between GFR and TSH in chronic kidney disease patients (Fig-1).

A linear regression line was founded between FT4 and GFR in CKD patients. It represents that as GFR decreased FT4 was also decreased, a straight line was obtained. It shows that they are directly proportional to each other (Fig-2).

According to the statistical analysis of the results obtained, changes in the thyroid functions were observed in chronic kidney disease patients, which were manifested in stage 3 chronic kidney disease.
This table represents that out of 65 patients 35 patients TSH was increased and 30 were normal and 8 patients out of 65 FT4 was decreased and 57 were normal. Now in those 35 patients whose TSH was increased there were 8 patients whose FT4 was decreased too and in the remaining 27 patients only TSH was raised while their FT4 was normal. So 8 patients show biochemical hypothyroidism and 27 patients shows biochemical subclinical hypothyroidism.

\section{DISCUSSION}

In the current study a significant correlation was observed between the free thyroxin, thyrotrophin and glomerular filtration rate in CKD patients. $P$ value was $<0.01$, and 0.000 with TSH and was 0.04 with FT4. This demonstrates that as glomerular filtration rate decreases thyroid functions are biochemically affected and biochemically developed subclinical and clinical hypothyroidism manifests itself.

There was a graded increased likelihood of subclinical hypothyroidism with progressively lower estimated GFR. Accordingly there was a significant inverse association between estimated GFR and TSH levels throughout the normal and high $\mathrm{TSH}^{7}$.

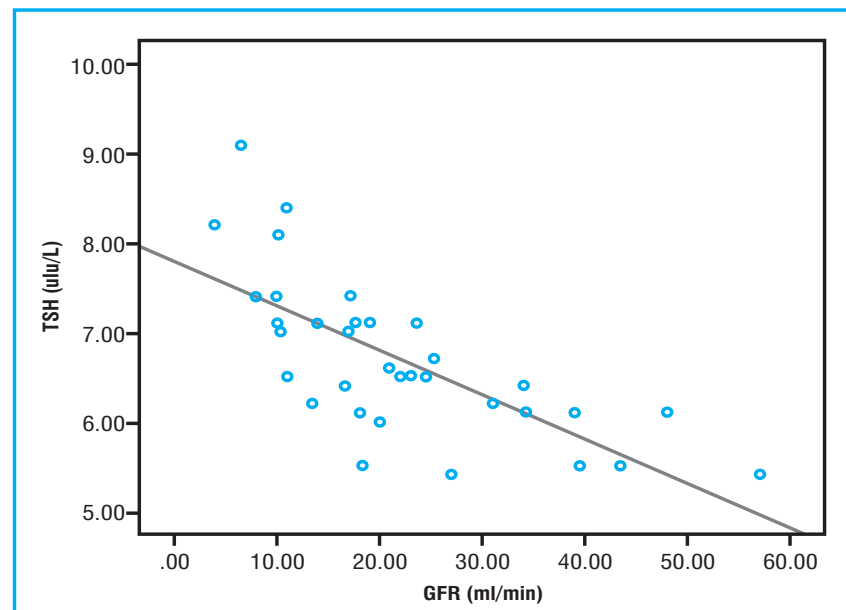

Fig.1: Regression line between GFR and TSH of chrnic kidney disease patients

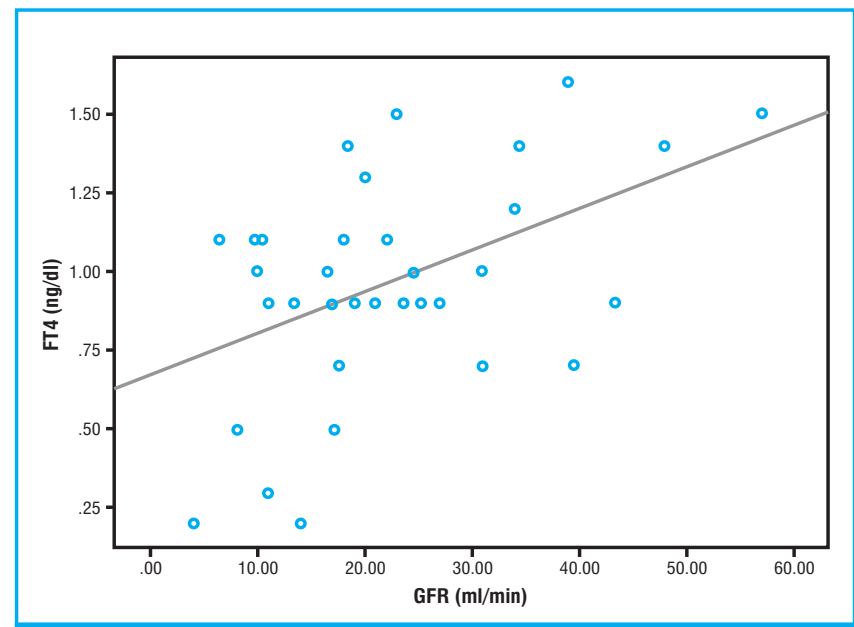

Fig.2: Regression line between GFR and FT4 of chronic kidney disease patients 
Prevalence of hypothyroidism was increased in persons with reduced GFR, ranging from $5.4 \%$ for persons with estimated GFR $\geq 90 \mathrm{ml} / \mathrm{min} / 1.73 \mathrm{~m}^{2}$ to more than $20 \%$ in person with estimated GFR $<60$ $\mathrm{ml} / \mathrm{min} / 1.73 \mathrm{~m}^{2,8}$.

The kidneys play important role in the metabolism, degradation and excretion of several thyroid hormones. It is not surprising; that impairment in kidney function leads to disturbed thyroid physiology ${ }^{8,13}$. All levels of the hypothalamic-pituitarythyroid axis may be involved, including alterations in hormone production, distribution and excretion. As a result, abnormalities in thyroid function tests are frequently encountered in uremia $^{13}$. However, the overlap in symptomatology between the uremic syndrome and hypothyroidism requires a cautious interpretation of these tests. Nevertheless, it is ordinarily possible in the individual uremic patient to assess thyroid status accurately by physical diagnosis and thyroid function testing ${ }^{13,14}$. Epidemiologic data suggest that pre-dialysis patients with chronic kidney disease have an increased risk of hypothyroidism ${ }^{8,13}$.

Lim speculated that the low thyroid state in uremia serves to defend against protein wasting and the misguided attempts to replete thyroid hormone stores may worsen protein malnutrition ${ }^{6}$.

In 2011 Alsaran, et al studied forty (40) CKD patients. They measured thyroid stimulating hormone, FT3 and FT4 before and immediately after hemodialysis session. Statistically significant increase in the postHD levels of FT3 and FT4 although the TSH levels did not show any significant change and suggested that measurement of TSH alone might be more reliable in the assessment of thyroid function in patients on regular HD than FT4 and FT3. Patients on regular HD suffer from chronic illness that is believed not to involve the thyroid gland. However, they may have low levels of serum thyroxin and tri-iodothyronine ${ }^{15}$.

Lippi et al conducted a study on relationship between thyroid status and renal function in general population of unselected out patients. He investigated the correlation between thyroid and kidney function. 13,383 results of serum creatinine and thyroid stimulating hormone were retrieved from the database when compared with euthyroid subjects, those with $\mathrm{TSH}<0.2 \mathrm{mlU} / \mathrm{L}$ and $>2.5 \mathrm{mlU} / \mathrm{L}$ had increased and decreased estimated glomerular filtration rate respectively and concluded that a mutual relationship was observed between kidney and thyroid status ${ }^{16}$.

Previous studies have suggested that there is increased prevalence of hypothyroidism in persons with reduced estimated glomerular filtration rate, independent of age, gender and race/ ethnicity. In addition, with progressively low glomerular filtration rate, there was graded increased likelihood of hypothyroidism ${ }^{8}$.

In a study carried out on 57 patients with chronic kidney disease, it was found that pre-dialysis T4 in 11 cases and T3 in 29 cases were lower than the normal range. After HD, the T4 levels in only three cases and T3 levels in fifteen cases were lower than normal. The remaining cases reverted to the normal state ${ }^{17}$.

Lo et al recently noticed that the prevalence of subclinical and clinical hypothyroidism increased with progressively lower levels of kidney function in a nationally representative cohort of US adults. Indeed, one in five persons with estimated GFR less than $60 \mathrm{ml} / \mathrm{min} / 1.73 \mathrm{~m}^{2}$ had laboratory or clinical evidence of hypothyroidism ${ }^{8}$.

The prevalence of subclinical hypothyroidism was increased in persons with progressively lower kidney function, ranging from $7 \%$ for persons with estimated GFR $\geq 90 \mathrm{ml} / \mathrm{min}$ per $1.73 \mathrm{~m}^{2}$ to $17.9 \%$ in persons with estimated GFR below $60 \mathrm{ml} / \mathrm{min}$ per $1.73 \mathrm{~m}^{2}$. Notably, when estimated GFR was subdivided in deciles instead of widely accepted diagnostic categories for CKD stages the prevalence of subclinical hypothyroidism was markedly increased among those in the first 
declile of estimated GFR $50.4 \pm 10 \mathrm{ml} / \mathrm{min} / 1.73 \mathrm{~m}^{2}$ compared with those in the highest estimated GFR $121 \pm 13 \mathrm{ml} / \mathrm{min} / 1.73 \mathrm{~m}^{2,7}$.

\section{Limitations}

This study has some weaknesses:

- The study did not adjust for the race, blood glucose levels, serum cholesterol and serum triglycerides.

- The study was based on the estimation of GFR rather than more accurate methods to measure actual GFR.

- The study was cross sectional.

- Other causes (thyroidal and non-thyroidal illnesses) of subclinical hypothyroidism were not identified.

\section{Advantages}

Despite the above weaknesses the study has several strengths:

- Patients with co-existing thyroid illness, using antithyroid drugs and those having clinical signs and symptoms of thyroid were excluded from the study.

- Subclinical hypothyroidism was diagnosed according to widely accepted clinical criterion i-e. TSH and free T4 were used instead of total T4.

- The method used to measure thyroid functions was uniform.

- The study used hospitalized and non-hospitalized pre dialysis CKD patients and a single reading is likely to show the steady state of thyroid functions tests.

- An adequate sample size was used in our study.

\section{CONCLUSIONS}

1. We found that reduced kidney functions were associated with biochemically thyroid dysfunction causing subclinical hypothyroidism and clinical hypothyroidism but most commonly causing subclinical hypothyroidism.

2. Inverse relationship exists between GFR and TSH.

\section{SUGGESTIONS}

1. The roles of clinical or subclinical hypothyroidism on physical function, cognitive function, quality of life and depression in CKD are unknown. However, health professionals caring for CKD patients should be cognizant that CKD and hypothyroidism may exhibit overlapping symptoms. Future investigations are needed to determine the value of assessing or screening for clinical and subclinical hypothyroidism among persons with CKD.

2. The possible adverse effects of subclinical hypothyroidism on cardiovascular risk associated with CKD are presently unknown, whether adult patients with CKD should be routinely screened for subclinical hypothyroidism requires further investigation.

\section{Copyright@ 27 Apr, 2013.}

\section{REFERENCES}

1. Coresh J, Selvin E and Stevens LA. Prevalence of chronic kidney disease in the United States. JAM 2007; 298(17):2038-47.

2. Hosseinpanah F, Kasraei, F, Nassiri AA, and Azizi F. High prevalence of chronic kidney disease in Iran: A large population based study. B MC Public health 2009; 9:44-52.

3. Levey AS, Eckardt KU, Tsukamoto Y, Levin A,Coresh J, and Rosset, J. Definition and Classification of Chronic Kidney Disease: a positive statement from kidney disease:Improving Global Outcomes (KDIGO). Kidney Int 2005; 67(6):2089-100.

4. Iglesias P and Diez JJ. Thyroid dysfunction and kidney disease. European journal of endocrinology 2009; (160):503-15.

5. Abozenah $H$, Shoeb S, Sabry A and Ismail $H$. Relation between thyroid hormonal concentration and serum levels of interleukin- 6 and interleukin-10 in patients with Non-thyroid illness including chronic kidney disease. IJKD 2008; (2):16-23.

6. Lim VS. Thyroid function in patients with chronic renal failure. Am J Kidney Dis 2001; 38: 80-84. 
7. Chonchol M, Lippi G, Salvagno G, Zoppini G, Muggo M and Targher G. Prevalence of subclinical Hypothyridism in patients with Chronic kidney Disease. Clin J Am Nephrol 2008: (3); 1296-1300.

8. Lo JC, Chertow MG, Go AS and Hsu CY. Increased prevalence of subclinical and clinical hypothyroidism in persons with chronic kidney disease. Kidney international 2005; 67:1047-52.

9. Enia G, Panuccio V, Cntupi S, Pizzim P, Tripepi G and Mallamaci F et al. Subclinical hypothyroidism is linked to microinflammation and predicts death in continuous ambulatory peritoneal dialysis. Dial Transplant 2007; (22):538-54.

10. ELISA, 2010 Wikipedia, the free encyclopedia.

11. Rongen, HA., Hoetelmans, RM., Bult, A., Van Bennekom, WP. Enzyme linked immunosorbent assays. J pharm Biomed Anal 1994; 12(4):433-62.

12. Larsen, K. Creatinine assay by a reaction kinetic approach. Clin Chem Acta 1972; (41):209-17.
13. Palmer BF and Henrich WL. Thyroid function in chronic kidney disease. Kidney Int 2011; 24: 11-13.

14. Wartosfsky and Land Burman KD. Alteration in thyroid function in patients with systemic illness "euthyroid sick syndrome" Endocr Rev 1982; 3:164-68.

15. Alsaran K,Sabry A, Alshahat H, Babgy E and Alzaharani F. Free thyroxine, free triiodothyronine and thyroid stimulating hormone before and after hemodialysis in Saudi patients with end stage renal disease: Is there any difference? Saudi J Kidney Dis Transpl 2011; 22(5):917-21.

16. Lippi G,Montagnana M,Targher G and Salvagno GL. Relationship between thyroid status and renal function in general population of unselected patients. Clinical chemistry 2008; 41:625-27.

17. Shamsadini S, Darvish-Moghaddam S, Abdollahi $\mathrm{H}$, Fekri AR, Ebrahimi HA. Creatinine, blood urea nitrogen and thyroid hormone levels before and after hemodialysis. East Mediter Health J 2006; 12(12):231-35

\section{AUTHOR(S):}

1. DR. MUHAMMAD ASIF

MBBS, M.Phil, FCPS 1 )

Lecturer Pathology

KMU Institute of Medical Sciences Kohat (KPK)

2. MR. MUHAMMAD AKRAM

M.Phil Biochemistry (FPGMI Lahore).

Assistant Professor Biochemistry

SFINHS/SKBZMDC, Shaikh Zayed Medical Complex Lahore.

3. MR. ATIF ULLAH

M.SC Chemistry

Districk Karak (KPK).

\section{Correspondence Address:}

Mr. Muhammad Akram

M.Phil Biochemistry (FPGMI Lahore).

Assistant Professor Biochemistry

SFINHS/SKZMDC, Shaikh Zayed Medical Complex Lahore. aakramskzmdc@yahoo.com 